\title{
EMPIRICAL RELATION TO ESTIMATE THE REDUCTION OF ROOT FILLET STRESS IN SPUR GEAR DUE TO ELLIPTICAL STRESS RELIEF FEATURES
}

\author{
M. S. Hebbal ${ }^{1}$, G.B. Kulkarni ${ }^{2}$, K. H. Prakash ${ }^{3}$,S. S. Patil ${ }^{4}$ \\ ${ }^{I}$ Basaveshwar Engineering College/ Dept. of Mechanical Engineering/ Bagalkot/India \\ ${ }^{2}$ Basaveshwar Engineering College/ Dept. of Mechanical Engineering/ Bagalkot/India \\ ${ }^{3}$ Basaveshwar Engineering College/ Dept. of Mechanical Engineering/ Bagalkot/India \\ ${ }^{4}$ Basaveshwar Engineering College/ Dept. of Mechanical Engineering/Bagalkot/India
}

\begin{abstract}
This work is an attempt to establish the empirical relations to predict the percentage of reduction of the root fillet stress in a spur gear due to elliptical stress relieffeatures (SRF). To modify the stress field in a spur gear to reduce the stress concentration using elliptical stress relief feature has added advantage over the circular stress relief features, because it has more parameters such as major diameter, ratio of major to minor diameter and orientation of its axis to regulate stress field. An investigation on root fillet stress is in a spur gear with an elliptical stress relieving feature is carried out using finite element method. Based on the finite element analysis carried out nine empirical relations are proposed. With these relations it is possible to predict the percentage of reduction of root fillet stress in spur gear within 2percentages of deviation.
\end{abstract}

Keywords: Spur gear, bending stress, stress relieffeature, FEA

\section{INTRODUCTION}

Based on the earlier research work standard method have been established by institutions like AGMA, ISO DIN etc. to compute the load carrying capacity of the gears. Recent research work show that, it is possible to reduced root fillet stress in spur gears by introducing stress relief features (SRF) of different shape and size at strategic locations. In view of this it is desirable to be have simple relations to be able to predict the minimum possible percentage of reduction of root fillet stress in a spur gear. Therefore a systematic study is carried out to establish a set of empirical relations to predict the possible reduction of stress in spur gear due to elliptical SRF.

The work of Dippery [1] showed that, stress concentration reduction is possible in generic shapes using holes as stress relief. In 1992 Srinivasalu [2] experimented by placing the holes in relatively low stress neutral axis of the bending of the gear tooth. In the earlier work, [3-4] the stress redistribution was studied using only circular holes. In recent work [5] even elliptical holes are used as stress relief feature to reduce the root fillet stress. Although it is relatively difficult to produce elliptical hole in comparison with circular hole, the advantages associated with elliptical SRF in redistributing the stress favorably ranks it better.
In all two hundred and seventy spur gear of different geometry are selected for analysis. The parameters of the spur gears considered for analysis in the present work have addendum factor, dedendum factor, module, and backup ratio equal to $1.25,1,10$ and 1 respectively. The magnitude of the pressure angle are $20.00,22.50$ and 25.00 and tool tip radius factors are $0.20,0.25$ and 0.30 respectively (Ref. Table -1 ).

Table -1 : Parameters of the Spur Gear Considered for Analysis

\begin{tabular}{|l|l|}
\hline Parameter & Magnitude \\
\hline Pressure angle $(\alpha)$ & $20^{\circ}, 22.5^{\circ}, 25^{\circ}$ \\
\hline Tooth fillet radius factor(r0) & $0.2,0.25,0.3$ \\
\hline No. of teeth $(\mathrm{Z})$ & $16,14,12$ \\
\hline Profile shift factor & 0 \\
\hline Gear ratio & 1 \\
\hline Load Applied & $400 \mathrm{~N} / \mathrm{mm}$ \\
\hline Module (m) & 10 \\
\hline Dedendum factor & 1.25 \\
\hline Addendum factor & 1 \\
\hline $\begin{array}{l}\text { Distance of SRF from end point on } \\
\text { critical section }\end{array}$ & $6.5,7.0 \quad 7.5$, \\
\hline
\end{tabular}


The elliptical stress relief parameters considered for analysis are: major diameter equal to $0.5,1.0,1.5$, and 2.0 the module and minor diameter is 1.75 times of major diameters. In all these cases the major axis makes 1650 with the horizontal.

\section{FINITE ELEMENT MODEL OF SPUR GEAR}

A program is developed in ANSYS Parametric Design Language (APDL) to automate the task of creation of model, meshing, applying boundary condition, choosing the appropriate density of the mesh depending on the stress gradient. A gear segment of three teeth is chosen as domain of finite element analysis. Fig-1 shows the geometric model of three teeth spur gear geometry. A point load of $400 \mathrm{~N}$ is applied at highest point of single tooth contact (HPSTC). Fixed boundary conditions are applied along both the radial edges and arc of the rim of the spur gear as shown in Fig-1.

The gear segment is meshed with Ansys eight node isoparametric (PLANE82) element as shown in Fig-2. Several mesh configuration of different mesh density are experimented to confirm the convergence of the finite element solutions. The maximum bending stresses obtained from finite element analysis are recorded.

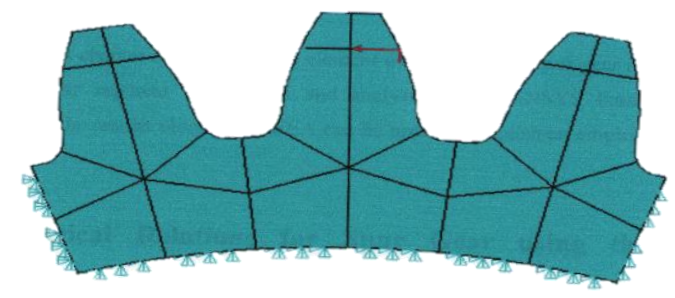

Fig -1: Geometric model and boundary conditions

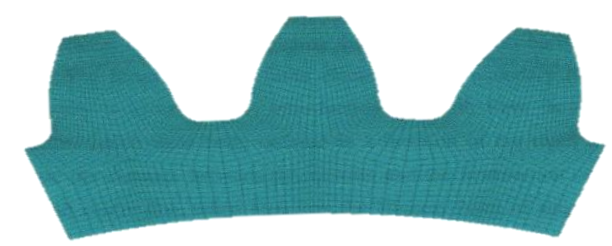

Fig-2: Meshed modal of spur gear segment
After recording the maximum bending stress, the elliptical stress relief feature at strategic location is included in the geometric model of the spur gear segment. The operation specified above are performed on the new spur gear model with elliptical SRF and maximum bending stresses are recorded. Typical stress distribution with and without the SRF are shown in Fig-3 and Fig-4. The parameters of the spur gear and the elliptical SRF are as given in Table No-2.

Table-2 : Parameters of the spur gear and Elliptical SRF

\begin{tabular}{|l|l|l|l|l|}
\hline \multicolumn{2}{|c|}{} & \multicolumn{2}{|l|}{$\begin{array}{l}\text { Elliptical } \\
\text { relief } \\
\text { parameters }\end{array}$} \\
\hline $\begin{array}{l}\text { Pressure } \\
\text { angle }\end{array}$ & $\begin{array}{l}\text { Number } \\
\text { of teeth }\end{array}$ & $\begin{array}{l}\text { Tooltip } \\
\text { radius } \\
\text { factor }\end{array}$ & $\begin{array}{l}\text { Major } \\
\text { diameter }\end{array}$ & $\begin{array}{l}\text { Minor } \\
\text { diameter }\end{array}$ \\
\hline 200 & 30 & 0.2 & 0.5 & 0.87 \\
\hline 22.50 & 40 & 0.25 & 1 & 1.75 \\
\hline
\end{tabular}

Fig-3 depicts the distribution of stress in spur gear around critical point without elliptical stress relief feature. The stress field modified due to elliptical stress relief feature is illustrated in Fig- 4

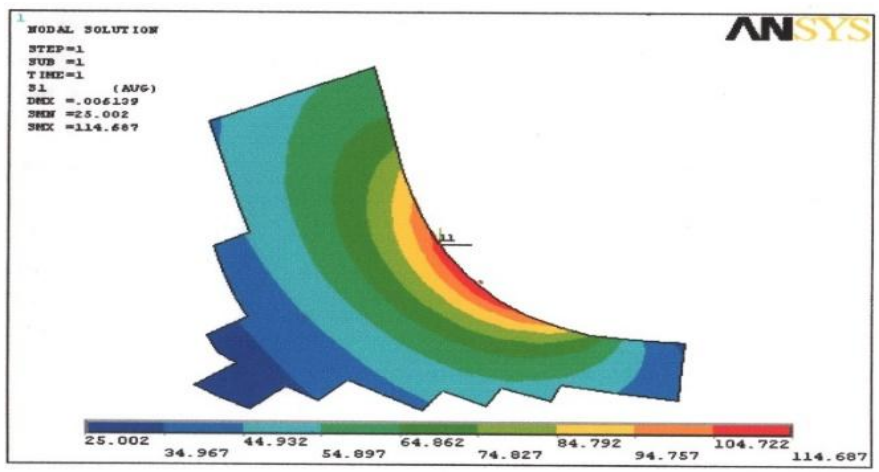

Fig -2: Stress field around critical point (without SRF)

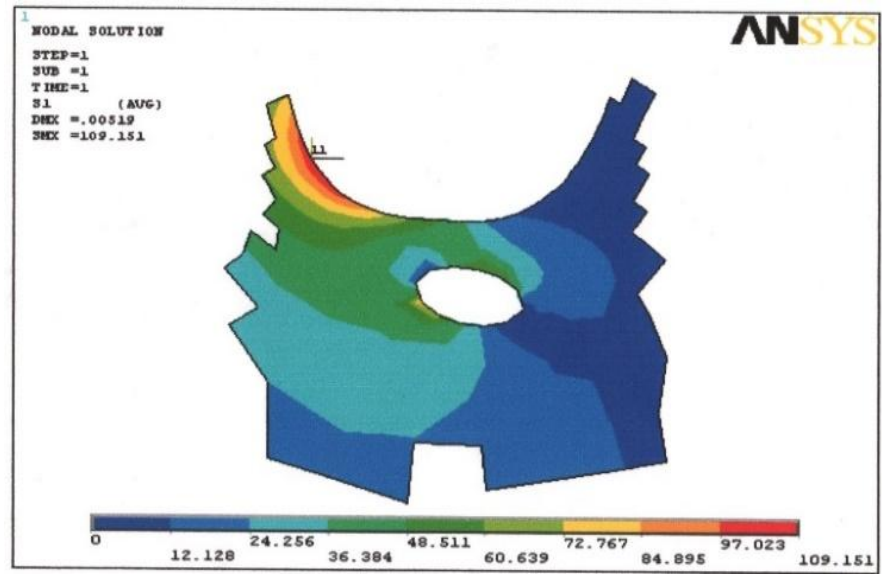

Fig -3: Stress field around critical point (with SRF) 


\section{RESULTS AND DISCUSSIONS}

Percentage of reduction in root fillet stress and number of teeth are plotted along $\mathrm{y}$ and $\mathrm{x}$ axes respectively in Chart no. 1-9 for different groups of pressure angle and tool tip radius factors. The results obtained by finite element analysis are fit to third order polynomial. The empirical relation by this curve fitting are given in Table No.3.

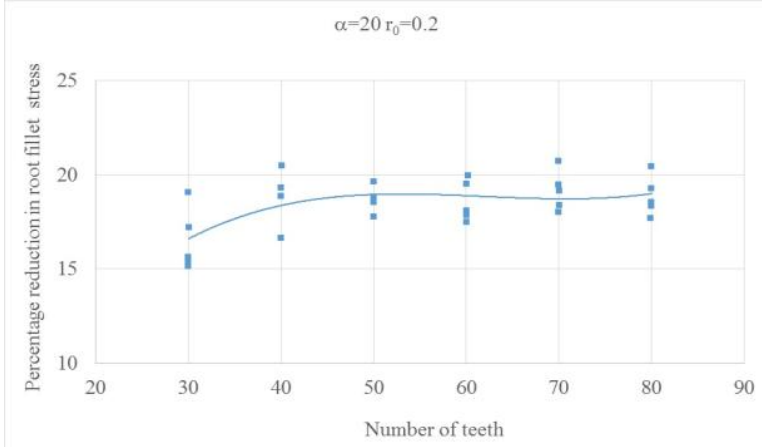

Chart -1: Percentage of reduction in root fillet stress vs number of teeth $(\alpha=20 \mathrm{r} 0=0.20)$

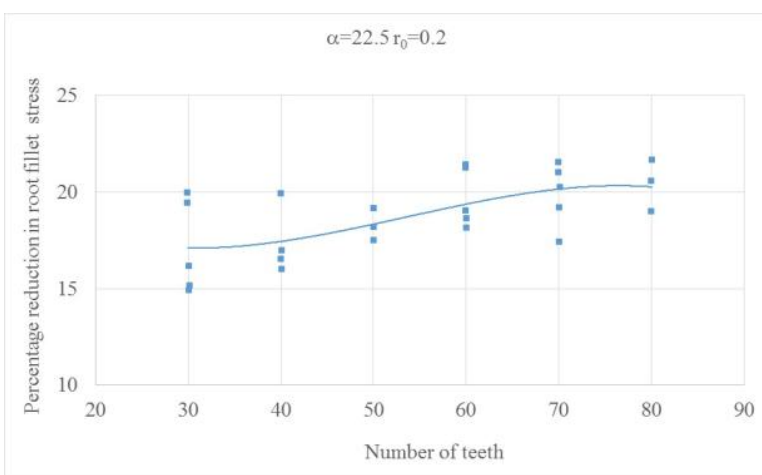

Chart -2: Percentage of reduction in root fillet stress vs number of teeth $(\alpha=22.5 \mathrm{r} 0=0.20)$

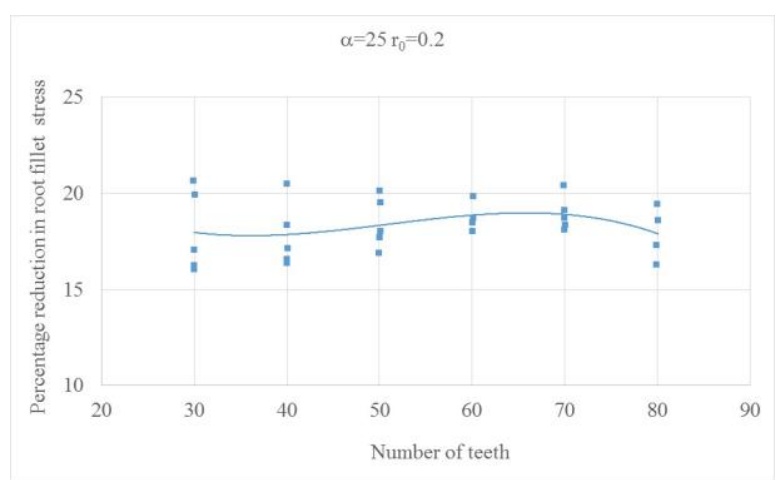

Chart -3: Percentage of reduction in root fillet stress vs number of teeth $(\alpha=25$ r $0=0.20)$

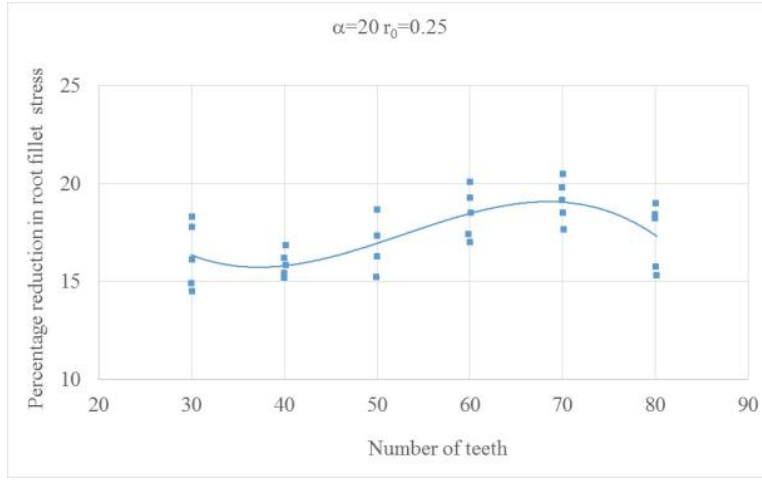

Chart -4: Percentage of reduction in root fillet stress vs number of teeth $(\alpha=20 \mathrm{r} 0=0.25)$

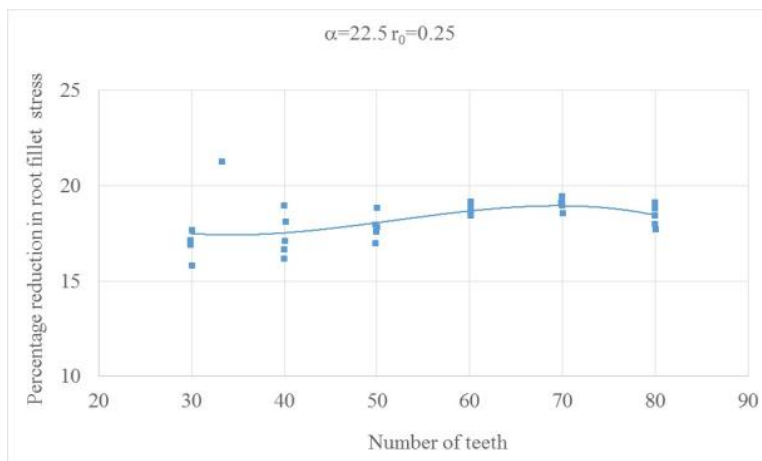

Chart -5: Percentage of reduction in root fillet stress vs number of teeth $(\alpha=22.5 \mathrm{r} 0=0.25)$

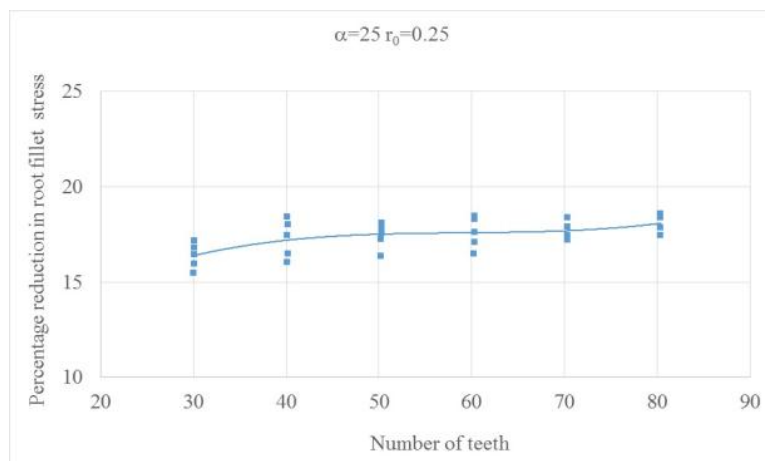

Chart -6: Percentage of reduction in root fillet stress vs number of teeth $(\alpha=25 \mathrm{r} 0=0.25)$ 


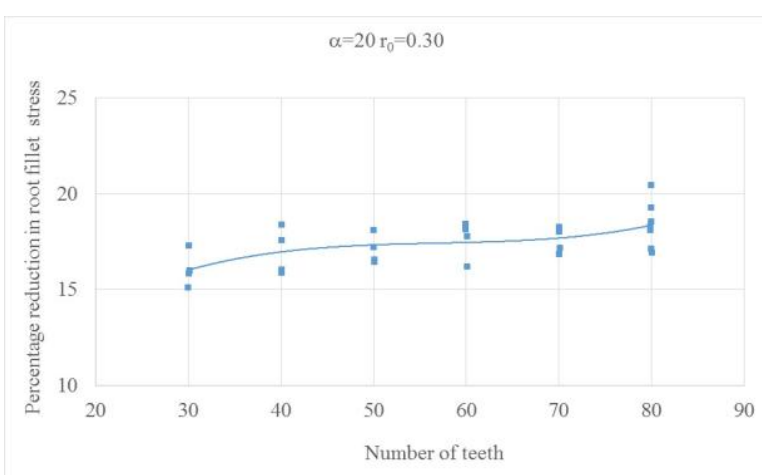

Chart -7: Percentage of reduction in root fillet stress vs number of teeth $(\alpha=20 \mathrm{r} 0=0.30)$

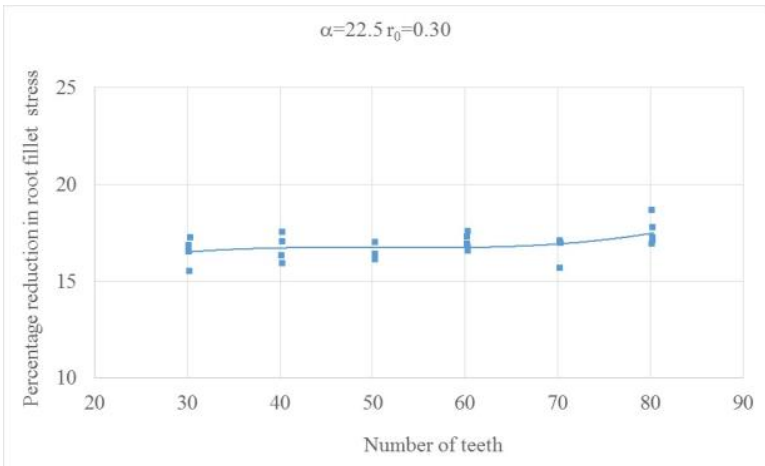

Chart -8: Percentage of reduction in root fillet stress vs number of teeth $(\alpha=22.5 \mathrm{r} 0=0.30)$

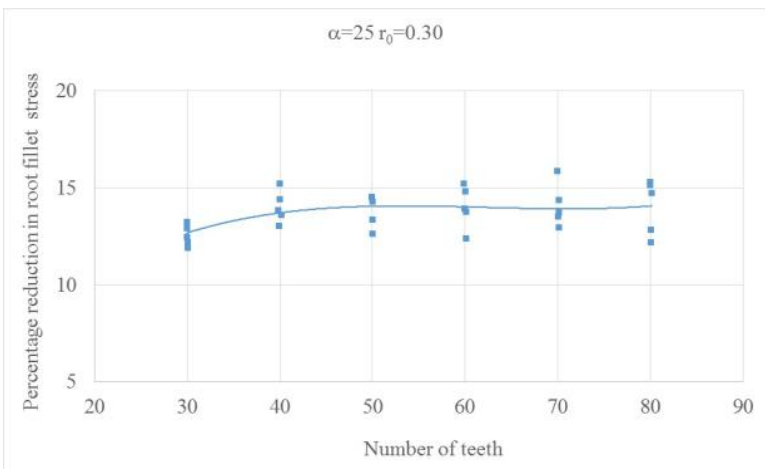

Chart -9: Percentage of reduction in root fillet stress vs number of teeth $(\alpha=25 \mathrm{r} 0=0.30)$

Table-3: Empirical Relation for Spur Gear Using 3rd Order Polynomial, $y=a x 3+b x 2+c x+d$

\begin{tabular}{|l|l|l|l|l|l|l|}
\hline \multirow{2}{*}{$\begin{array}{l}\text { Sl. } \\
\text { No. }\end{array}$} & a & b & c & d & \multicolumn{2}{|l|}{\begin{tabular}{l} 
Gear Parameters \\
\cline { 4 - 7 } \\
angle
\end{tabular}} \\
\hline 1 & $9.47 \mathrm{E}-4$ & $-1.75 \mathrm{E}-$ & 1.05 & -1.79 & 200 & $\begin{array}{l}\text { Tool tip } \\
\text { radius } \\
\text { factor }\end{array}$ \\
\hline
\end{tabular}

\begin{tabular}{|l|l|l|l|l|l|l|}
\hline & & 2 & & & & \\
\hline 2 & $\begin{array}{l}-7.68 \mathrm{E}- \\
5\end{array}$ & $1.17 \mathrm{E}-2$ & -0.49 & 23.26 & 22.50 & 0.20 \\
\hline 3 & $7.29 \mathrm{E}-5$ & $1.12 \mathrm{E}-2$ & -0.52 & 25.39 & 250 & 0.20 \\
\hline 4 & $\begin{array}{l}-1.96 \mathrm{E}- \\
4\end{array}$ & $3.06 \mathrm{E}-2$ & -1.44 & 37.29 & 200 & 0.25 \\
\hline 5 & $1.07 \mathrm{E}-3$ & $1.60 \mathrm{E}-2$ & -0.68 & 24.23 & 22.50 & 0.25 \\
\hline 6 & $4.60 \mathrm{E}-4$ & $\begin{array}{l}-8.51 \mathrm{E}- \\
2\end{array}$ & 0.54 & 4.90 & 250 & 0.25 \\
\hline 7 & $6.35 \mathrm{E}-4$ & $\begin{array}{l}-1.19 \mathrm{E}- \\
2\end{array}$ & 0.75 & 0.43 & 200 & 0.30 \\
\hline 8 & $7.29 \mathrm{E}-4$ & $\begin{array}{l}-1.12 \mathrm{E}- \\
2\end{array}$ & 0.55 & 6.24 & 22.50 & 0.30 \\
\hline 9 & $5.62 \mathrm{E}-4$ & $\begin{array}{l}-1.04 \mathrm{E}- \\
2\end{array}$ & 0.63 & 1.62 & 250 & 0.30 \\
\hline
\end{tabular}

\section{CONCLUSIONS}

From the present study the following conclusions are arrived. The elliptical SRF can modify the stress field better than the circular SRF since the elliptical SRF have more parameters to augment the redistribution of the stress field favorably. From chart no.1-9 it is evident that it is possible to predict the percentage of reduction in root fillet stress closely. The maximum deviation of the prediction is about 2 percentage only.

\section{ACKNOWLEDGEMENTS}

This work is supported by Technical Education Quality Improvement Program Phase-II, Basaveshwar Engineering College, Bagalkot.

\section{REFERENCES}

[1]. Dippery R E, "A study in stress concentration optimization Using Boundary Element Methods", PhD. Dissertation, University of Cincinnati, 1990

[2]. Srinivasalu B, "Spur Gears- A new Approach in to Tooth Design" American Gear Manufacturers Association, Technical Paper 92FTMSI. 2

[3]. Fredette, M. Brown, "Gear Stress Reduction Using Internal Stress Relief Feature", Transaction of ASME Journal of Mechanical Design, Vol. 119, December 1997, PP. 518 521

[4]. M. S. Hebbal, V. B. Math, C.M. Veerendrakumar, S. B. Kerur, "An Approach to the redistribution of Root Fillet Stress in Spur gear", National Conference on Recent Advances in Design engineering ( RADE 2007)

[5]. M. S. Hebbal,V. B. Math, B. G. Sheeparamatti, "The Reduction of Root Fillet Stress in Spur Gear Using Circular and Elliptical Stress Relieving Feature", International Conference, US National Congress on Computational Mechanics, San Francisco, USA,22-26July 2007. 